Article

\title{
Differences, Constraints and Key Elements of Providing Local Sharing Economy Services in Different-Sized Cities: A Hungarian Case
}

\author{
Katalin Czakó $^{1, *(D)}$, Kinga Szabó ${ }^{2}$, Marcell Tóth ${ }^{2}$ and Dávid Fekete ${ }^{1}$ \\ 1 Kautz Gyula Faculty of Economics and Business Administration, Széchenyi István University, \\ Egyetem Square 1, 9026 Győr, Hungary \\ 2 Doctoral School of Regional Science and Business Administration, Széchenyi István University, \\ Egyetem Square 1, 9026 Győr, Hungary \\ * Correspondence: ckatalin@sze.hu; Tel.: +96-613-789
}

Received: 30 June 2019; Accepted: 14 August 2019; Published: 17 August 2019

check for updates

\begin{abstract}
The business models of sharing economy services can differ from each other in different-sized cities. This paper provides a deeper understanding of the implementation of locally operating services for car, bicycle and office sharing in the urban environment. Our goal is to reveal the differences between the capital city and an economically well-developed city in order to provide beneficial findings to the development of the presently operating services, or to the possible implementation of future services. Methodology of the paper applies the Business Model Canvas approach (BMC). We introduce a comparative analysis using data from the Hungarian database, which records details of all the publicly visible sharing economy services countrywide. The results show that BMC can reflect the main differences, constraints and key elements in the business models of sharing economy services. We can say that, in the case of a bike sharing service operated in the non-capital city, there is more segmentation than seen in the same service in the capital. There are significant price differences, especially in the case of long-term tickets. The number of inhabitants and private capital remain the biggest constraints in the case of car-sharing services, but there is also a possibility of implementation in the non-capital cities by applying small-scale services with a good value proposition and segmentation.
\end{abstract}

Keywords: service-based economy; sharing economy; car-sharing; bike-sharing; shared office; Business Model Canvas

\section{Introduction}

The rationale of this research is to highlight the importance of supporting the currently increasing trend in sharing economies. Available comparative analyses in the literature that focus on the differences between capital and non-capital cities (the latter having smaller populations) in having the economic potential to give a place for sharing economy services, are rarely available. Our basic assumption is that while there are effective sharing economy service models in capital cities, due to the modern concept of sharing economy, it is also crucial to implement and improve services in other cities. Applying the Business Model Canvas (BMC) approach in the analysis of local cases enables this comparison and will find differences, constraints, and key elements, especially in the strategies of the service provisions.

We formulate the comparative analysis of some local cases around three research questions:

(Q1) What are the main differences in the business models of those sharing economy services which are represented in both the capital and in the chosen city?

(Q2) Besides the number of inhabitants, what are the main constraints in implementing a sharing economy service in a chosen city, which is operating well in the capital? 
(Q3) What are the key elements of implementing a sharing economy service in the chosen city, which is operating well in the capital city?

Hungary is an interesting case for analyzing sharing economy services, because the sharing economy services in Budapest (the capital) are in their upcoming trend. There are more and more opportunities available each year, which means the market of sharing economy services and the taste of customers toward the sharing economy are not saturated. Besides adapting some European business models, there are many unique ways for sharing economies, which can provide customized business model elements that can be valuable input into sharing economy practices. In this paper we analyze local sharing economy services: Only those ones that have no national, European or worldwide coverage. This step contributes to the comparative analysis, in which we focus on services which are represented both in the capital and in the chosen city, and services which are presented only in the capital. The "chosen city" is Győr, located in the western part of Hungary. In terms of economic output, it is the richest city after Budapest. The world's biggest engine factory operates in the city, and the car manufacturing industry is the most important economic strength of Györ [1]. Due to the so-called Győr Cooperation Model, the stakeholders (local government, local companies, university and civil organizations) of the city are working together successfully on the development of the city [2]. We introduce the multifaceted application of the Business Model Canvas with the goal of revealing the main differences between the business models of presently operating sharing economy services in the capital and in the chosen city. We also reflect on the key elements and constraints in implementing sharing economy services, which are present in the capital city and not present in the chosen city. We focus on bike-, car- and office-sharing services. Although the sharing economy has been part of human society for a long time, it has taken a new form and has grown considerably during the last two decades. With transformations in technology and the increase in per capita income, the transport industry has registered phenomenal growth in the last few decades, with the number of passenger cars reaching over 1.2 billion in 2015 for the first time ever [3]. Increasing numbers of cars and massive migration into cities have resulted in congestion, traffic jams, parking problems, increased accidents and deaths, as well as growing pollution in cities. These have given birth to new ideas in car sharing in a variety of ways, such as shared taxies, single rides, carpools, ride-sourcing and many more. Implementation of bike sharing is less costly than car sharing. It is interesting to look at how it is shaping its market in a city which lacks the attributes of a capital city.

The first part of this article highlights the modern concepts of the sharing economy and gives a short summary of the evolution of car-sharing services in Europe, the largest car-sharing region based on membership data. After that, we introduce the research concept, comparing the local sharing economy services in a capital and a chosen city, which could also be appropriate for making multi city comparisons. Findings in the article are presented in the last section. The main differences, key elements and constraints are highlighted as practical contributions. The application of BMC is presented as a theoretical contribution.

\section{Theoretical Background}

The modern concept of the sharing economy has evolved not only based on a variety of quantifiable factors. The theoretical framework of the paper firstly highlights the concepts which are the closest to our understanding of sharing economy services. After this, there is a short collection of statistical data represented in order to underline the rationale of the analysis.

\subsection{Modern Concepts in the Sharing Economy}

With massive growth of cities, lack of parking space, traffic congestion and air pollution, sustainable urban transport has become a modern necessity. According to Suchanek and Szmelter-Jarosz, growing cities and their populations have become a challenge for today's researchers, local authorities and business decision-makers. One of the problems troubling the current politics is meeting the requirements of sustainable transport, especially when urban residents present the opposite needs [4]. This has 
given birth to car and bike sharing in urban and semi-urban areas. A variety of models of the sharing economy have emerged based on local conditions and the needs of customers. Growth of cities and populations are not the only increasing factors of a sharing economy. Consumer behavior, like new aspects in sustainable mobility or changing working habits, are also strengthening the need of sharing economies. These aspects include the weakening desire for ownership, economic stagnation and economic crises, reduction in disposable income due to growing unemployment, urbanization, evolution of new innovative sharing concepts, environmental considerations and availability of new technological tools and platforms [5]. Consumption can be based on time, space or at a fixed price. The consumer chooses such access when they are not able to afford the objects in question, or they do not wish to own them for reasons of maintenance, space, cost and so forth. The consumer is acquiring consumption time with the item and, in market-mediated cases of access, is willing to pay a premium price for use of that object [6]. Thus, the consumer-object relationship in access-based consumption may be different from that in ownership. The owner has the right to regulate or deny access to use, sell and to retain any profits yielded from the object's use, as well as to transform its structure [7].

According to Grondys, the sharing economy is treated as an alternative consumption model, aiming to increase the efficiency of the resources used and create a new value for society [8]. Development of new technologies, particularly Internet, IT platforms, social media and IT applications have facilitated the evolution of this model. Fransi et al. hold the view that the sharing economy has become a new socioeconomic activity that allows the co-creation, production, distribution and consumption of goods and services between individuals, driven by Web 2.0 and e-word-of-mouth [9]. Access-based services have emerged as an alternative and/or complementary to traditional ownership-based services and they are enabled by means of Smart Product-Service Systems (SPSSs) that integrate smart products and e-services into a single solution [10].

According to Rifkin [11], although a property continues to exist, it is less likely to be exchanged in the market. Instead of buying and owning properties and goods, consumers want access to goods and prefer to pay for the experience of limited and temporary access. As stated by Chen [12] and Marx [13], ownership is no longer the ultimate expression of consumer desire. During the last decade we have seen a proliferation of access systems in the market place that go beyond traditional forms of access. For example, access can be gained through memberships to clubs or organizations, where multiple products owned by a company can be shared [14,15].

Modernity characterizes the current social conditions in which social structures and institutions are increasingly unstable and are undergoing change and therefore they cannot serve as frames of reference for human actions and long-term life strategies [16]. Increasingly, institutions, people, objects, information and places considered solid during the last century have tended to dematerialize and liquidize [17]. Similarly, consumer identity and ethics are also becoming more fluid. Values are constantly changing. Emotional, social and cultural ownership embedded in a property is becoming flexible, transient and liquid. Access has emerged as a way to manage the challenges of a liquid society [18].

The increase in the costs of acquisition and maintenance for ownership over time, the instability in social relationships, as well as the uncertainties in the labor markets have rendered ownership a less attainable and more precarious consumption mode than it once was [19]. Many people have started wondering why they should own when benefits could be enjoyed at a fraction of the total cost with easy access and no storage and maintenance requirements. With density as a major concern of the re-urbanization movement, sustainable development, apartments and condos have increased in city centers, offering alternatives to the long commutes and the reliance on cars that dominate suburban living [20]. Urban settings have created a new set of problems that can be addressed by the sharing economy. Unlike earlier generations of information or technology-based enterprises, sharing enterprises rely on a critical mass of providers and consumers who are sufficiently close to each other or to other amenities to make their platforms work, often finding value in the very fact of the beneficial spill-overs from proximity [21]. For example, Uber transports people from one common area to another 
without involving idle driving or parking requirements. The driver picks up the passenger from the nearest area and after dropping picks up another passenger where the previous passenger was dropped, almost eliminating idle driving or parking. Moreover, the passengers need not navigate the heavy traffic themselves, as is the case with self-driving.

Growing awareness of environmental issues has also played its role in the evolution of the sharing economy. Air pollution in cities due to the growing vehicular population has transformed the thinking process of at least a section of the population. This section, which is no longer environmentally conscious, wishes to add new vehicles, causing additional congestion and air pollution. According to the 2014 survey by the Center for the New American Dream, 90\% of Americans believe that the way they live produce too much waste, and $70 \%$ agree that Americans consume more resources and produce more waste compared to other countries. A total of $60 \%$ agree that the sharing economy lowers environmental impact [22]. Commenting on the environmental impact the report of Demailly [23], "clothing, vehicles, furniture, telephones, televisions, toys, sporting goods, home improvement, and gardening tools are all examples of the shareable goods that represent about a quarter of household expenditure and a third of household waste, not to mention the energy used to produce them".

Our understanding of the sharing economy highlights that it is an economic model which allows optimum use of individual and social assets and resources. The sharing economy in its present form is a relatively new phenomenon. Previous business models were based on the idea of complete ownership of assets and processes. Such ownership many times resulted in underutilization of assets and capacities which led to increased costs for the business enterprises and wastes of resources. The sharing economy is a highly flexible economic network that allows people to exchange tangible and intangible goods with one another in different forms of business models. Social, economic and environmental considerations are the driving force behind sharing economy models in the recent years. Socially, the desire for ownership has weakened; economically, individuals want to earn some income through temporary use their assets; and environmentally, such use helps in mitigating congestion and pollution. These models have taken a variety of forms depending on the needs of the people in different-sized countries and cities.

\subsection{Evolution of the Sharing Economy through Car Sharing in Europe}

Integration of digital technology with transport systems has further enhanced the transformation. Motor vehicles have provided mobility to people, goods and services in a way never seen before in the history of mankind. Today, almost $80 \%$ to $90 \%$ of the global population uses automobiles in one way or another. This movement has given birth to interactions between civilizations, cultures and customs. The tourism industry and businesses have expanded globally, across national borders. Products and services produced in any part of the world can have ingredients from many countries and continents. Similarly, finished products-agricultural as well as industrial—move rapidly across national borders. Even short shelf-life items like fruits, flowers and vegetables produced in one continent can be found in markets on another continent. The growth of the tourism industry has given rise to mélange and assimilation of cultures and customs. In short, the globalization process has been possible because of the growth of the automobile industry and its integration with digital technology. This has given birth to what is called smart transportation.

As the social status associated with car ownership became diluted and the problems of traffic jams, parking space, accidents and high operating costs (price of fuel, insurance cost, toll charges and parking fees, local air pollution, carbon dioxide emissions leading to climate change, noise pollution and road damage) started getting worse, people were forced to rethink car ownership. Moreover, there are millions who cannot afford to own a car but wish to use and experience car ownership for a limited duration on a payment basis. Environmental considerations due to very high $\mathrm{CO}_{2}$ emissions also played a role in reshaping the concept of car ownership. Another significant problem with the car ownership model is the inefficiency of their utilization. Most cars are designed to seat five people, however the normal occupancy is only one or two. Moreover, most cars are only utilized during a small 
part of the day, leaving them idle most of the time. All these considerations gave birth to what is known as car sharing. Many car sharing organizations (CSOs) or transport network companies (TNCs) were established in the 1990s, mostly in Europe. These car sharing organizations were initially supported by governmental grants. Their system was quite simple-a few vehicles were involved in shared usage by a group of individuals. Due to the lack of technology and the grassroots of the car sharing system being neighborhood-based programs, it was very difficult to transfer them into a business venture model. Urbanization, congestion and modern technology gave a boost to car sharing companies.

Historically, the first commercial car sharing can be traced to a cooperative known as "Sefage" (Selbstfahrergemeinschaft), which initiated services in Zurich, Switzerland, in 1948 and remained in operation until 1998 [24]. This early effort was mainly motivated by economic reasons, since there were individuals who could not afford to purchase a car and instead preferred to share one. However, this was a limited experiment confined to a small area. Gradually the carsharing concept became popular in many European countries for the reasons given in the previous paragraph. New concepts and companies came into existence with different concepts of car sharing, including "Procotip" in France, 1971 to 1973; "Witkar" in Amsterdam, 1974 to 1988; "Green Cars" in Britain, 1977 to 1984 ; Sweden's "Bilpoolen" in Lund, 1976 to 1979, "Vivallabil" in Orebro, 1983 to 1998; and a "bilkooperativ" in Gothenburg, 1985 to 1990 [25,26].

According to Figure 1, a BCG report shows in 2016, that car sharing in Europe will expand relatively quickly and widely. It is estimated that the number of people living in large urban areas will grow further, and this number will be around 81 million people in Europe and 385 million globally by 2021. About 46 million people in Europe will have a valid driving license and about 14 million people will be registered with a car sharing service. About 1.4 million people will be active users, who use the car sharing service several times per month.

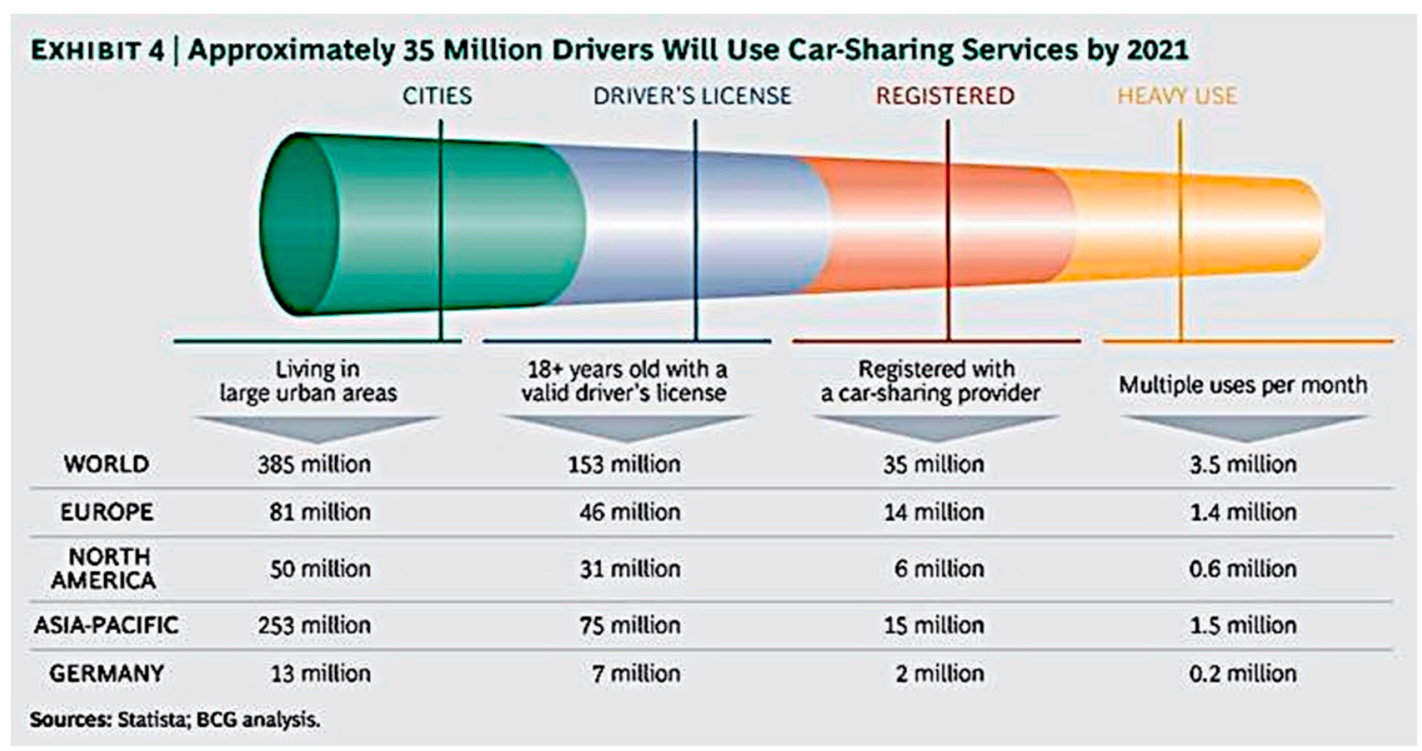

Figure 1. Expected growth of global car-sharing services by 2021. Source: Adapted from Bert et al. [27].

A growing concern regarding climate change and a yearning for social embeddedness by localness and communal consumption has made the "collaborative consumption"/"sharing economy" an appealing alternative for consumers [28,29]. The chart below (Figure 2) provides a bird's-eye view of the growth of car-sharing services in Europe. 


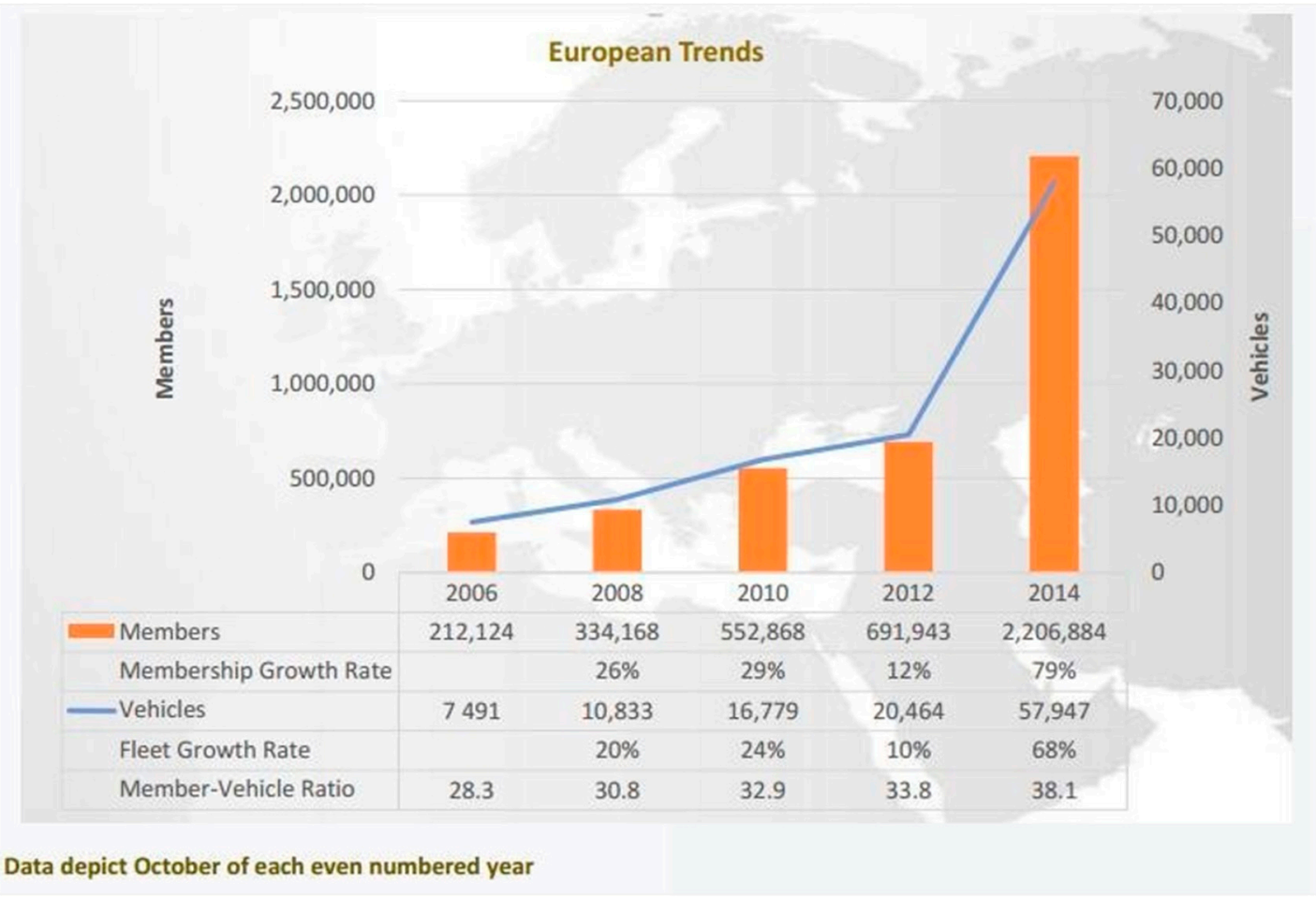

Figure 2. European trends. Source: Adapted from Shahen-Cohen [30].

Today, Europe is considered to be the largest car-sharing region based on membership, accounting for $46 \%$ of worldwide membership and $56 \%$ of global fleets [30]. In recent years, the big automakers and car rental companies in Europe have joined hands to form car-sharing companies, to keep their hold on the market.

\section{Materials and Methods}

As it was mentioned before, the modern concept of the sharing economy has evolved not only based on a variety of quantifiable factors. Applying the elements of BMC in local cases will find differences, constraints and key elements, especially in the strategies of the sharing economy service provisions. Comparative analyses in the literature, which focus on differences in the aspects of use of sharing economy services between the capital and big cities in non-capital positions, are rarely available.

Classically, the use of BMC has targeted creating new businesses and projects or implementing new activities within a company or organization. In our case, we apply BMC as an analytical tool in two ways:

- $\quad$ BMC is applied here in order to reveal the main characteristics of presently operating sharing economy services in the capital, and through this we define constraints and key elements of possible implementation in the chosen city.

- $\quad$ BMC is applied here in order to reveal the main characteristics of presently operating sharing economy services in the capital and the city, and through this we define the main differences between the business models and allows us to elaborate on possible improvement directions in the city.

\subsection{Database, Data Collection and Research Boundaries}

Our continuously refreshed and enlarged data base serves national data from eight big cities, and the capital of Hungary, since 2016 from Hungarian sharing economy service providers. It involves the following data used in the study: 
- $\quad$ Price of the services,

- type,

- target,

- owners,

- date of foundation, and

- date of implementation in the given city.

These data input were nominated as general data.

As it was mentioned in the introduction the chosen cities are Budapest and Győr. We followed some basic approach in demarcation of the research field:

- In the selection process it was important to pick a city where the number of sharing economy services is close to the capital's.

- Those services which have national coverage were taken out from the comparison. Other services which were founded based on social media communities were also removed.

- It was also the dominant approach to pick a city in which the economic output is enough to establish new and green services, which serves the local society.

As a link to the general data, we collected the elements of BMC in the case of Budapest, along with Győr:

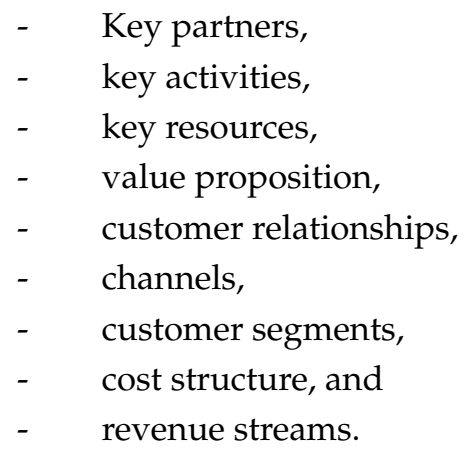

For the data collection of the elements of BMC we used publicly available websites, news and other documents (marketing brochures, service maps, annual reports and other reports). With this step, we show in this study that BMC elements have good functions for analyzing present services in order to consider their further development, or implementation of replicas in other economic and social environments.

\subsection{Steps and Phases of the Comparison}

Following the approach of comparing services in the capital and the other city, it was easy to compare the 15 above-listed fields of data. This detailed comparison gave the main differences, and key elements and constraints, of implementation. Following this concept of analyses gives the opportunity to compare sharing economy services on the basis of the capital-noncapital dimension, but also in a city to city context. Involving more and more service providers in this context can give important input to the further development or more effective operation of sharing economy services. In our opinion, screening value propositions are a special input in the comparison of sharing economy services. They can show how environmental protection, or "thinking green", is presented in the services.

Figure 3 shows the above-detailed steps as the concept of analysis applied in this paper. 


\begin{tabular}{|c|c|c|c|c|}
\hline \multicolumn{5}{|c|}{$\begin{array}{c}\text { Database of Hungarian sharing economy service } \\
\text { providers }\end{array}$} \\
\hline $\begin{array}{l}\text { Demarcate } \\
\text { the research } \\
\text { field }\end{array}$ & $\begin{array}{l}\text { General data } \\
\text { from data } \\
\text { base }\end{array}$ & $\begin{array}{l}\text { Adding } \\
\text { the } \\
\text { elements } \\
\text { of BMC }\end{array}$ & $\begin{array}{l}\text { Data to Data } \\
\text { comparison }\end{array}$ & $\begin{array}{c}\text { Differences } \\
\text { Key } \\
\text { elements } \\
\text { Constraints }\end{array}$ \\
\hline
\end{tabular}

Figure 3. Concept of analysis. Source: Self-made.

\section{Results and Discussion}

\subsection{Screening the Cities: Number and Type of Sharing Economy Services}

In the case of a survey undertaken in Budapest and Győr, it was revealed that the number of enterprises and service providers in the area of sharing economy is transparent. They show an increasing tendency towards participation in the sharing economy, based on data from 19 service providers in Budapest (capital) and 4 in Györ (city). The survey also revealed that the local sharing economy enterprises are primarily concentrated in the areas of transportation and shared office space.

Based on the available information presented in Table 1, common services in the capital and the city are car sharing, shared bicycle services and co-working offices. There are no shared bicycle networks without a dockage, shared motor bicycle or scooter services, or shared small transportation bike services in Győr. There are specialized social movements or activities based on the principle of the sharing economy in both cities, mainly presented in social media platforms. As we focused on recovering the main differences and constraints of the implementation of sharing services, we did not involve social media-based sharing activities or movements. Firstly, we detailed services which can represent the main differences between the two cities: Car sharing, shared bicycle and motor sharing services, as well as co-working offices. Next, we highlighted the main differences in BMC of these type of activities.

Table 1. Services of the sharing economy in the surveyed cities (Explanation: + service is presented in the city, ++ service is present in the city with more providers, and (+) there is a system in town but does not target all member of society).

\begin{tabular}{ccc}
\hline Sharing Economy Services & Capital City (Budapest) & Chosen City (Györ) \\
\hline Co-working offices & ++ & + \\
Shared car services & ++ & + \\
Shared bicycles & + & + \\
Shared bicycle (without any dockage) & + & \\
Shared motor bicycles & + & \\
Shared scooters & + & \\
Shared small transportation bike & + & + \\
Other sharing economy activities & + & \\
\hline
\end{tabular}

\subsubsection{Car Sharing}

The following five companies occupy important positions in this market in Budapest: GreenGo, MOL Limo and Drive Now in Budapest follow the traditional business-to-customer model of car sharing services. Another car sharing company in Budapest, Avalon Carsharing, is undergoing an internal transformation. The company will phase out traditional customer services and confine itself to consultancy services on car sharing. BeeRides, an airport car sharing service, has been providing services at Ferihegy Airport since 2015. Although it is a Hungarian-owned company, since 2018 it has been expanding at several airports in Germany. Of the services analyzed, this is the only peer-to-peer (or in other words C2C) service. GreenGo was the first of the city car dealerships in the capital. The number of vehicle fleets based on available, refreshed data are: 
- $\quad$ MOL Limo: 450 vehicles,

- GreenGo: 300 vehicles, and

- $\quad$ DriveNow: 280 vehicles.

In Györ there is a car sharing activity, namely Audi 1.2 GO, which is an internal business-to-employee car sharing service of Audi meant for employees for their movements on official duty and for movements within the factory premises. Audi has devised this online system as a perk to employees to earn their loyalty, and to make their work more efficient by facilitating their movements. Under this sharing economy model the maintenance cost of cars is borne by Audi. Given the small size of Győr and large number of Audi employees who are served by the above-mentioned car-sharing system, an independent car-sharing enterprise has not been able to launch car-sharing services in Győr yet. There is only one car-sharing enterprise, namely Up! City, in the Slovakian capital, Bratislava, which is three times larger than Györ, and this enterprise operates with a fairly small fleet of cars.

\subsubsection{Bike, Motorcycle and Scooter Sharing}

Besides car sharing, sharing of other transport vehicles, particularly bikes, motorcycles and scooters, is also important. GyorrBike was the second of the towns with county rights, and started operating in 2015 in Györ. Among the cities of similar size, bicycle sharing appeared later in Debrecen (2016) and Pécs (2019). Among the rural systems, GyőrBike is the largest in the country in terms of the number of bicycles, docking stations and stations. MOL BuBi has been in operation since 2014 and is the largest domestic system in every respect, maintained by the Budapest Transport Center (BKK). Additionally, MOL, which is one of the largest Hungarian companies, steps up as a sponsor for the promotion of service and mode of transport.

Donkey Republic is a Danish-owned company. The docked smartphone application was launched in 2017 in the Hungarian capital. It currently operates 200 bicycles.

BlinkeeCity is a Polish company and has launched its electric scooter-sharing service in Budapest in 2018 with 77 vehicles. Although it is not yet present in Györ, it has begun its expansion in the countryside, and since summer 2019, there are also scooters in Pécs. Lime, an electric scooter, started operations in Budapest in 2019 with 200 scooters. The US-owned firm is not planning a rural expansion yet.

Among these, the most popular and common in the two surveyed cities is bike sharing, which has a tradition going back several years. Bike sharing operates both in Budapest and Győr; thus, we can see the correlation between the number of infrastructural elements and population of the two cities (Table 2).

Table 2. Correlation in bike sharing systems: Infrastructural elements and population.

\begin{tabular}{cccccc}
\hline Service Provider & Bikes & Stations & Dockages & Town & Population \\
\hline MOL BuBi & 1526 & 126 & 2687 & Budapest & $1,749,734$ \\
GyőrBike & 180 & 31 & 362 & Győr & 130,094 \\
MOL BuBi (\% of population) & $0.08 \%$ & $0.007 \%$ & $0.1 \%$ & Budapest & \\
GyőrBike (\% of population) & $0.1 \%$ & $0.02 \%$ & $0.3 \%$ & Győr & \\
\hline
\end{tabular}

If we look at the per capita ratios, we can see that there are closing values in the number of bikes. The number of bikes available is $0.08-0.1 \%$ for one citizen. Considering the population, there are relatively more stations and dockages in Györ than in Budapest. From this data we can see that the number of bikes can depend on the local population, and the number of stations and dockages are mostly infrastructural elements which are implemented based on other approaches than number of inhabitants. We consider this fact in the BMC analysis.

In addition to the bike sharing, Budapest has enterprises providing electrically operated scooters and motorbikes. Both of these enterprises are new in the Hungarian market. BlinkeeCity started 
its services in 2018 and deals with electrically operated motorbikes, while Lime started its services in spring 2019 and deals with electrically operated scooters. Transport bike provider, Cargonomia, which started its operation in 2018, operates transport bike services in Budapest. These transport bikes must be dropped at the same place they are picked up from. In the price comparison, we observed significant differences:

From the price differences in Table 3 we can observe that prices show big differences, especially prices of long-term tickets. We include in this comparison only those prices which are presented in both cities.

Table 3. Price differences in bike sharing. Source: Self-made based on available data.

\begin{tabular}{lc}
\hline & GyörBike (\% in Prices of MOL Bubi) \\
\hline Registration & $120 \%$ \\
\hline Tickets & \\
\hline $24 \mathrm{~h}$ & $80 \%$ \\
$72 \mathrm{~h}$ & $80 \%$ \\
Weekly & $50 \%$ \\
Half year & $46 \%$ \\
Yearly & $47 \%$ \\
\hline Usage fee & \\
\hline For less than $30 \mathrm{~min}$ & Free (also in case of MOL Bubi) \\
For less than $60 \mathrm{~min}$ & $50 \%$ \\
For less than $90 \mathrm{~min}$ & $55 \%$ \\
For less than $120 \mathrm{~min}$ & $60 \%$ \\
\hline
\end{tabular}

\subsubsection{Co-Working Offices}

Co-working offices involve the use of the same office space by different enterprises on a time-sharing basis, when these enterprises do not require any specialized equipment. Such co-working offices could also facilitate networking and sharing of experiences, in addition to the cost savings. Freelancers, home-office workers and start-ups were mainly using this type of facility in both the surveyed cities. We found nine examples in Budapest and one in Győr. Same examples have also been found in other towns in Hungary. On the basis of BMC there are no significant differences among the users of co-working offices. They are working on the same model. Their principal aim is to access the structured market with minimum cost on infrastructure, as most of their business activities and documents are online. The exception in their business model is that they are providing a different variety of connected services: Buffet services, cafés, libraries, computers, consultations and workshops. The biggest co-working office in Hungary is Loffice, which also provides co-working offices at Lake Balaton during the summer months for those who wish to work during their holidays.

\subsection{Business Model Canvas of Service Providers}

We highlight information here from the above selected service providers, observing their communication through their websites and news connected to them. With the goal of recovering the main differences between the capital and the chosen city of Hungary, we represent the elements of BMC. To do so, we focus on main differences, in order to implement or improve service models working well in smaller cities.

\subsubsection{Key Partnerships}

Sharing economy models also provide solutions to ecosystem problems of large cities and not only in capitals. The selected services enter into partnerships with a variety of local players, such as municipal corporations, local people and other economic and social players and institutions. For car-sharing companies the partnerships with local municipalities and social organizations are important, 
since the cars are parked in public spaces and car sharing helps in reducing pollution and congestion in cities. There are private service providers behind MOL Limo, GreenGo and BeeRides. In the case of Győr Audi is the biggest engine producer and exporter in Hungary. Therefore, a car sharing service in a closed system is provided for its 12,000 employees in order to decrease the usage of cars and infrastructure of the industrial district of Audi. We can observe that, in the case of the capital, there are more private players behind bike sharing. The partnerships evolve in a variety of ways. In the case of MOL BuBi, which is a traditional bike-sharing enterprise, there is a direct partnership with the MOL Company and the state-owned Budapest Transport Company (BKK), and indirect partnerships with municipalities of the districts. In the case of GyörBike there is a direct partnership with the municipality of the city, which founded the project. There are partnerships in Győr with Széchenyi István University and ETO FC, which is a local football club. These are not financial partnerships but are mostly important due to the placing of stations. At the university campus and student hostels, local football stadium and other sport-related venues there are several dockages. The survey revealed that the dockage at the university campus is the most-used service station in Gyobr. This close linkage with the university is not visible in Budapest, where there is not a concentration of dockages close to student hostels. The survey revealed that the bike-service providers who do not have dockages do not seem to have similar partnerships with local institutions. Lime, an American electrical roller-sharing company, which entered the Hungarian market in 2019, does not have partnerships with local institutions presented on their website. On the contrary, this company has many partnerships with US universities, where it has been operating for some time. For transport bikes, partnerships are very important as the users are expected to provide parking at pick-up and drop-off points. In the case of co-working offices, interaction happens naturally with other users of the office space, which leads to some sort of networking with the local enterprises.

\subsubsection{Key Activities and Resources}

In the case of bike-sharing companies, on the basis of BMC there is no difference between the service providers in Budapest and Györ. In both cases the bikes, the dockages, the stations, the IT applications and their maintenance are the most important elements for the bike-sharing enterprises.

\subsubsection{Value Proposition}

In the case of car sharing we could reflect the following value propositions:

Environment protection: According to the survey there are many differences in the value proposition of different car-sharing enterprises. GreenGo, which entered the market first, places maximum emphasis on environment protection. Its entire fleet of cars is electric operated.

Having a car: The motto of MOL Limo is simple. It says: You have a car. DriveNow, which is the latest entrant into the market, has a completely different motto. It provides only luxury vehicle BMW and Minis to the richer segment of society.

Parking: Parking fees are involved in most car-sharing services. It is therefore important to secure free parking spaces from the local authorities, as this is an important element of the overall cost of car sharing. As a result of such initiatives, electrical cars with green number plates have been allowed free parking facilities in Budapest. The fleet of GreenGo is $100 \%$ electric-operated cars, while the fleet of MOL Limo has a mixture of petrol-driven and electric-operated cars.

Short visits: BeeRides is trying to enter into a partnership with Budapest Airport for free parking spaces, as the main profile of the company is to utilize the cars of those who are leaving the city on short visits, from when they leave the airport until their return. Under this system the car owners do not have to pay a parking fee at the airport. Moreover, they earn some money by renting out their cars during their absence on visits abroad. In the case of bike-sharing services, the most important value propositions are health and the environment. Therefore, the model of a sharing economy is based on sustainability and environmental considerations, against the traditional ownership of assets. Thus, the 
value proposition is the main focus for all players participating in the sharing economy. In the case of co-working offices, the main focus is reduction of cost.

\subsubsection{Customer Relations}

Based on their respective market segments, service enterprises are focusing on their customers through their websites and other online communication channels. Since car-sharing services are still confined to a comparatively small segment of the population, communication within the segment is comparatively easy.

\subsubsection{Distribution Channels and Segmentation of Customers}

In the case of car-sharing services in these two cities, there is a clear market segmentation. On the contrary, in the case of bike sharing services, the customers are primarily confined to the student community, young sport lovers, and hospital visitors.

\subsubsection{Cost Structure and Revenue Streams}

For car-sharing enterprises in Budapest, the car rental fee is the most important source of revenue. On the expenditure side, maintenance of the cars, operation of the system and the salaries of employees are the most significant costs. DonkeyRepublic, a bike-sharing company in Budapest, does not have any linkage with docking places. Their bikes could be picked up and dropped at any place in the city. On the basis of the Business Canvas Model its business model is very similar to the traditional bike-sharing systems with dockages, but they do not incur any expenditure linked to the dockages. Their income is from the donations of users. In the case of other bike-sharing service providers, the main costs are the operation of IT platforms and cost of dockages. In co-working offices, the renting fee is the most obvious revenue stream for providers.

\subsection{Differences, Constraints and Key Elements}

Our goal was to reveal the differences between a capital city and an economically well-developed city by leaning on the modern concept of a sharing economy, which is led by not only the quantifiable factors like population, but also by aspects of consumer behavior. Social, economic and environmental considerations were the driving forces behind sharing economy models in the recent years, e.g., the desire for ownership is not so high anymore and there is obviously a financial motivation behind sharing.

\subsubsection{Main Differences}

While there is only one big service provider with dockages and stations in bike sharing in each city, there are several smaller providers in Budapest that are competing for their market share and use alternative ways to handle the cycles or collect the fee of service.

On the basis of BMC, in smaller towns there is a tendency toward segmentation, as observed in Győr. This segmentation is obvious in the car-sharing market. In the case of sharing of bikes, the segmentation is more in terms of specific groups such as students, hospital visitors and sport persons. The direct partnerships are more visible in Györ in terms of the groups of users, while the partnerships are clearer in Budapest service providers.

In the case of the capital, private ownership is more behind bike sharing. There are more service providers. Prices in Győr are significantly less for long-term tickets.

Through the analysis the role of key partners and the ownerships could be reflected. There are two general results from this: We can see the presence of foreign direct investment in the case of services in the capital, and we can see university and sport clubs as dominating key partners in the case of the chosen city. 


\subsubsection{Constraints}

Although the car-sharing economy is expanding globally, what still really matters is the size of the cities and towns. Population remains the major factor for expansion of car-sharing services. As mentioned earlier, even in Bratislava, which is a smaller town compared to Budapest, there is only one car-sharing enterprise. The value proposition of environmental protection is linked to a wider target of possible users. As this type of service has private owners in the capital, profitability is also an important factor, which is dependent on the size of the local population. Publicity is also important to make people aware, and to create demand for these services. On the other hand, obstacles in sharing economy services can be overcome if the services are confined to a specific segment of people, as in the case of the car-sharing service to and from the airport, and for employees of a big enterprise in Győr.

Based on this, we can suggest that in case of cities with a smaller population, implementing car sharing to specific customer segments can be less risky, as it is operating in a different business model in the analyzed cases. A small-scale, segmented service supports and motivates users in their environmental consideration. We can see a trend of diversification in the analyzed bike-sharing services of the capital. This is also visible in the business models or strategies of different car-sharing service providers.

As a significant difference, it could be observed how between the capital's and the city's business models that population as a constraining factor is not the only one behind. Not having the critical mass of possible users of the services leads us to the finding that instead of following a capital's route, the creation of smaller, segmented services can be more successful than implementing widespread ones. In case of the capital the motivation behind the diversification were market-related factors like saturation. In case of an economically well-developed city with a lower population, the motivation behind the segmentation can be linked more to the modern concept of a sharing economy, which is based not only on quantifiable factors like population. Due to this, in our opinion, the optimal strategy for smaller cities is to support small-range, segmented services with a proper value proposition.

\subsubsection{Key Elements}

Value propositions are an important and well-presented factor of the analyzed sharing economy services. In the case of car sharing there are different value propositions, such as environmental protection, using premium category cars, having a car and designated travel routes. In the case of bikes, scooters and rollers, the main value position is predominantly environmental protection and health.

In the case of bike-sharing services, the number of bikes can depend on the local population. The number of stations and dockages is mostly infrastructural and are implemented based on other approaches than number of inhabitants. We consider this fact in the BMC analysis.

Best practice could be recovered in the transportation bike-sharing service, because in Budapest, apart from infrastructure, partnership is also a key element. The bikes can be picked up and dropped at the place of the designated partner or organization. The maintenance of the bikes and the operation of the online application are the two important cost factors. The system runs on a non-profit basis. Based on the voluntary donations received, the system is maintained. The main value proposition is sustainability and environmental considerations, and to help with last-mile connectivity.

The BMC approach was appropriate to reflect the key elements of the different value propositions in car sharing: Environmental protection, having a car, parking, short visits, health and environment, as well as a reduction of cost.

\section{Conclusions}

Based on the survey it is clear that the number of sharing economy enterprises is on the rise in Hungary, but they are still primarily confined to the capital. Amongst all the cities, Budapest remains the principle arena of their activities. The aim of this article was to examine various sharing economy models and their differences in Budapest and Győr, based on the BMC. The article also examined the 
obstacles in further expansion of sharing economy models in Győr, and the key elements for successful operation of this models. On the basis of the above we have come to the following conclusions: From the above-reflected differences we can conclude, especially in case of bike sharing, that the number and type of users are the key factors in implementing sharing economy services, and not the population. We can see that despite the fact that Györ has a smaller population, it can operate sharing services successfully, with key partnerships for the strategic placement of dockages, like the local university or sport clubs. Additionally, it is important to note that car sharing is presented in a given segment, so despite the fact that the population of Győr is not critical in terms of car sharing, the biggest corporation there is creating its own green solution for decreasing the usage of cars in its area. The abovementioned conclusions do not mean that service improvement in both cities is not needed. There are constraints and key elements which need to be considered in order to increase the number of these services.

We can say that BMC elements had good functions for analyzing the present services in order to consider their further development or implement their replicas in other economic and social environments. BMC could reflect the main differences, constraints and key elements in the models of sharing economy services. We can say that, in the case of the bike-sharing service operating in Györ, there is more segmentation than for the same service in Budapest. There are also significant price differences. In Győr, long-term tickets prices are more than 50\% less than in Budapest. We can conclude that Györ would like to attract more long-term users than Budapest. The number of inhabitants and ownership are the biggest constraints in implementing car-sharing services, but there is also a chance for implementation by applying good value propositions and segmentation.

Author Contributions: K.C. and D.F. had the initial idea of the manuscript and undertook the conceptualization; K.S. performed the literature review; K.C. designed the research methodology and analyzed the data; M.T. collected the data and provided the database; K.C. and K.S. wrote the paper with the supervision of D.F.; funding acquisition and administration was provided by D.F.

Funding: Preparation of the paper was supported by Count Istvan Bethlen Research Centre.

Acknowledgments: Data collection to the database applied in the study was supported by the "Center for cooperation between higher education and the industries at Széchenyi István University (FIEK)" under grant number GINOP-2.3.4-15-2016-00003.

Conflicts of Interest: The authors of the above presented research declare no conflict of interest.

\section{References}

1. Fekete, D. Economic Development and Economic Governance through the Example of the City of Győr. Deturope Cent. Eur. J. Tour. Reg. Dev. 2018, 10, 97-115.

2. Fekete, D. Latest Results of the Győr Cooperation Model. Polgári Szle. Gazdasági És Társadalmi Folyóirat 2018, 14, 195-209. [CrossRef]

3. Worldometers. Available online: http://www.worldometers.info/cars (accessed on 12 January 2017).

4. Suchanek, M.; Szmelter-Jarosz, A. Environmental Aspects of Generation Y's Sustainable Mobility. Sustainability 2019, 11, 3204. [CrossRef]

5. Ogilvy Eyes Wide Open, Wallet Half Shut: The Emerging Post-Recession Consumer Conscious-ness. Available online: http://www.wpp.com/wpp/marketing/consumerinsights/eyes-wide-open-wallets-half-shut (accessed on 20 March 2016).

6. Durgee, J.; O'Connor, G. An Exploration into Renting as Consumption Behaviour. Psychol. Mark. 1995, 12, 89-104. [CrossRef]

7. Snare, F. The Concept of Property. Am. Philos. Q. 1972, 9, 200-206.

8. Grondys, K. Implementation of the Sharing Economy in the B2B Sector. Sustainability 2019, 11, 3976. [CrossRef]

9. Fransi, E.C.; Hernandez-Soriano, F.; Rosell, B.F.; Daries, N. Exploring Service Quality among Online Sharing Economy Platforms from an Online Media Perspective. Sustainability 2019, 11, 3690. [CrossRef]

10. Lu, D.; Lai, I.K.W.; Liu, Y. The Consumer Acceptance of Smart Product-Service Systems in Sharing Economy: The Effects of Perceived Interactivity and Particularity. Sustainability 2019, 11, 928. [CrossRef]

11. Rifkin, J. The Zero Marginal Cost Society; Palgrave Macmillan: New York, NY, USA, 2014. 
12. Chen, Y. Possession and Access: Consumer Desires and Value Perceptions Regarding Contemporary Art Collection and Exhibit Visits. J. Consum. Res. 2009, 35, 925-940. [CrossRef]

13. Marx, P. The Borrowers. New Yorker. 2011. Available online: http://www.newyorker.com/magazine/2011/01/ 31/the-borrowers (accessed on 15 August 2019).

14. Belk, R. Sharing. J. Consum. Res. 2010, 36, 715-734. [CrossRef]

15. Giesler, M. Consumer Gift System: Netnographic Insights from Napster. J. Consum. Res. 2006, 33, $283-290$. [CrossRef]

16. Bauman, Z. Liquid Times: Living in an Age of Uncertainty; John Wiley \& Sons: Cambridge, UK, 2013.

17. Ritzer, G. Sociological Theory; McGraw-Hill: New York, NY, USA, 2010.

18. Bardhi, F.; Eckhardt, G.M.; Arnould, E.J. Liquid Relationship to Possessions. J. Consum. Res. $2012,39$. [CrossRef]

19. Cheshire, L.; Walters, P.; Rosenblatt, T. The Politics of Housing Consumption: Renters as Flawed Consumers on a Master Planned Estate. Urban Stud. 2010, 47, 2597-2614. [CrossRef]

20. Leinberger, C.B. The Option of Urbanism: Investing in a New American Dream; Island Press: Washington, DC, USA, 2007.

21. Davidson, N.M.; Infranca, J.J. The Sharing Economy as an Urban Phenomenon. Yale Law Policy Rev. 2016, 34, 215-279.

22. Center for a New American Dream. Analysis Report: New American Dream Survey 2014. 2014. Available online: https://newdream.s3.amazonaws.com/19/d9/7/3866/NewDreamPollFinalAnalysis.pdf (accessed on 2 December 2017).

23. Demailly, D.; Novel, A.S. The sharing economy: Make it sustainable. Studies 2014, 3, 14-30.

24. Harms, S.; Truffer, B. The Emergence of a Nation-Wide Carsharing Co-Operative in Switzerland. 1998. Available online: http://www.communauto.com/images/Nation\%20wide\%20CS\%20org\%20Suisse.pdf (accessed on 22 March 2018).

25. Britton, E.; World Carshare Associates. Carshering 2000, Sustainable Transport's Missing Link; The Commons and Ecoplan: Paris, France, 2000. Available online: https://networkdispatches.files.wordpress.com/2013/10/ carshare-2000-final-report.pdf (accessed on 16 August 2019).

26. Strid, M. Sweden-Getting Mobilized. In Carsharing 2000: Sustainable Transport's Missing Link; Britton, E., World Carshare Associates, Eds.; The Commons and Ecoplan: Paris, France, 2000; pp. 84-90.

27. Bert, J.; Collie, B.; Gerrits, M.; Xu, G. What's Ahead for Car Sharing? The New Mobility and Its Impact on Vehicle Sales; Boston Consulting Groups: Seattle, WA, USA, $2016 . \quad$ Available online: https://www.bcgperspectives.com/content/articles/automotive-whats-ahead-car-sharing-newmobility-its-impact-vehicle-sales/\#chapter1 (accessed on 23 February 2016).

28. Albinsson, P.A.; Perera, B.Y. Alternative marketplaces in the 21st century: Building community through sharing events. J. Consum. Behav. 2012, 11, 303-315. [CrossRef]

29. Botsman, R.; Rogers, R. Beyond Zipcar: Collaborative consumption. Harv. Bus. Rev. 2010, 88, 30.

30. Shahen, S.; Cohen, A. Innovative Mobility Carsharing Outlook: Carshering Market Overview, Analysis, and Trends: Winter 2016. Available online: http://innovativemobility.org/wp-content/uploads/2016/02/ Innovative-Mobility-Industry-Outlook_World-2016-Final.pdf (accessed on 12 May 2019).

(C) 2019 by the authors. Licensee MDPI, Basel, Switzerland. This article is an open access article distributed under the terms and conditions of the Creative Commons Attribution (CC BY) license (http://creativecommons.org/licenses/by/4.0/). 